\title{
Transition Metal-Free, Visible-Light Mediated Synthesis of 1,10-Phenanthroline Derived Ligand Systems
}

DOI:

10.1039/C7CC03903D

Document Version

Accepted author manuscript

Link to publication record in Manchester Research Explorer

\section{Citation for published version (APA):}

Edwards, A., Geist, A., Müllich, U., Sharrad, C., Pritchard, R., Whitehead, R., \& Harwood, L. M. (2017). Transition Metal-Free, Visible-Light Mediated Synthesis of 1,10-Phenanthroline Derived Ligand Systems. Chemical

Communications- Royal Society of Chemistry, 53, 8160-8163. https://doi.org/10.1039/C7CC03903D

\section{Published in:}

Chemical Communications- Royal Society of Chemistry

\section{Citing this paper}

Please note that where the full-text provided on Manchester Research Explorer is the Author Accepted Manuscript or Proof version this may differ from the final Published version. If citing, it is advised that you check and use the publisher's definitive version.

\section{General rights}

Copyright and moral rights for the publications made accessible in the Research Explorer are retained by the authors and/or other copyright owners and it is a condition of accessing publications that users recognise and abide by the legal requirements associated with these rights.

\section{Takedown policy}

If you believe that this document breaches copyright please refer to the University of Manchester's Takedown Procedures [http://man.ac.uk/04Y6Bo] or contact uml.scholarlycommunications@manchester.ac.uk providing relevant details, so we can investigate your claim.

\section{OPEN ACCESS}




\section{Accepted Manuscript}

This article can be cited before page numbers have been issued, to do this please use: A. C. Edwards, A. Geist, U. Müllich, C. A. Sharrad, R. Pritchard, R. Whitehead and L. M. Harwood, Chem. Commun., 2017,
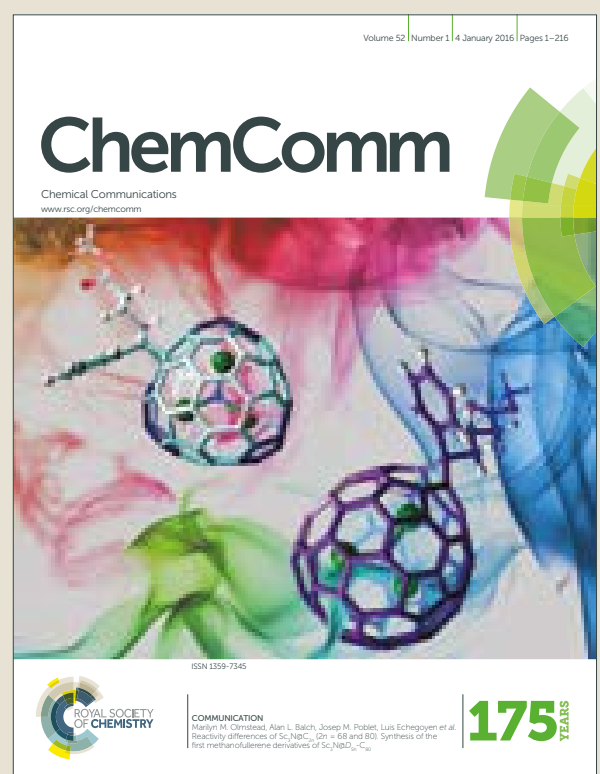

This is an Accepted Manuscript, which has been through the Royal Society of Chemistry peer review process and has been accepted for publication.

Accepted Manuscripts are published online shortly after acceptance, before technical editing, formatting and proof reading. Using this free service, authors can make their results available to the community, in citable form, before we publish the edited article. We will replace this Accepted Manuscript with the edited and formatted Advance Article as soon as it is available.

You can find more information about Accepted Manuscripts in the author guidelines.

Please note that technical editing may introduce minor changes to the text and/or graphics, which may alter content. The journal's standard Terms \& Conditions and the ethical guidelines, outlined in our author and reviewer resource centre, still apply. In no event shall the Royal Society of Chemistry be held responsible for any errors or omissions in this Accepted Manuscript or any consequences arising from the use of any information it contains. 


\section{ChemComm}

\section{COMMUNICATION}

\section{Transition Metal-Free, Visible-Light Mediated Synthesis of 1,10- Phenanthroline Derived Ligand Systems}

Received 00th January 20xx, Accepted 00th January 20xx

DOI: $10.1039 / \times 0 \times x 00000 x$
Alyn C. Edwards, ${ }^{a}$ Andreas Geist, ${ }^{b}$ Udo Müllich, ${ }^{b}$ Clint A. Sharrad, ${ }^{c}$ Robin G. Pritchard, ${ }^{a}$ Roger C. Whitehead, ${ }^{a}$ and Laurence M. Harwood*d

www.rsc.org/

\begin{abstract}
A broad range of 1,10-phenanthroline substrates was efficiently C$\mathrm{H}$ functionalised, providing rapid, gram-scale access to substituted heteroaromatic cores of broad utility. Furthermore, this $\mathrm{C}-\mathrm{H}$ functionalisation pathway was extended to the synthesis of previously inaccessible, ultra-soluble, 2,9-bis-triazinyl-1,10phenanthroline (BTPhen) ligands for advanced nuclear fuel cycles.
\end{abstract}

The heteroaromatic, 1,10-phenanthroline scaffold is a ubiquitous structural motif in chelating agents, herbicides, luminescent materials and supramolecular assemblies. ${ }^{1-9}$ The cis-locked nature of the 1,10-phenanthroline core provides several distinct chemical and structural advantages over the more common 2,2'-bis-pyridyl system, including enhanced metal-ion complexation kinetics ${ }^{10}$ and nucleic acid intercalation potential. ${ }^{11,12}$ The development of synthetic methods for the selective functionalisation of the tricyclicscaffold has the potential to augment and expand such applications. Since its development over 40 years ago, ${ }^{13,14}$ Minisci-type $\alpha-C-H$ functionalisation has undergone a remarkable renaissance ${ }^{15-18}$ and now acts as a mainstay transformation in the development of new, medicinally active pharmacophores. ${ }^{19-22}$ In more recent years, visible-light photoredox catalysis has emerged as a powerful alternative to traditional Minisci-type $\mathrm{C}-\mathrm{H}$-tunctionalisations, allowing selective and highly efficient heteroarylation reactions to proceed at ambient temperatures. A vast array of nonconventional, synthetic transformations has since been achieved using photocatalysis and a diverse number of $\alpha$ carbon-centered radical coupling partners including acids, ${ }^{14,19,23}$ amines, $^{24,25}$ amides $^{26-30}$ (rig. 1), ethers ${ }^{31-33}$, sulfinamides ${ }^{34}$ and boronic acids ${ }^{35-37}$.

a. School of Chemistry, The University of Manchester, Oxford Road, Manchester, M13 9PL, UK.E-mail: roger.whitehead@manchester.ac.uk

b. Karlsruhe Institute of Technology (KIT), Institute for Nuclear Waste Disposal (INE), Karlsruhe, Germany. E-mail: andreas.geist@kit.edu

c. School of Chemical Engineering, The University of Manchester, Oxford Road,

Manchester, M13 9PL, UK.E-mail: clint.a.sharrad@manchester.ac.uk

d. Department of Chemistry, The University of Reading, Whiteknights, Reading, RG6 6AD, UK. E-mail: I.m.harwood@readinq.ac.uk

+ Electronic Supplementary Information (ESI) available: Full synthetic details, key NMR spectra, solvent exlraclion procedures and additional dald, TRLFS selup anid procedures and X-ray crystallographic data. See DOI: 10.1039/xOxx00000x
Despite their many advantages, a large number of photoredox-catalysis methodologies involve the use of rare, expensive and toxic transition-metal catalysts, making them unsuitable for industrial deployment. ${ }^{30-41}$ More recent research efforts have focused on the generation of the sulfate radical anion $\left(\mathrm{SO}_{4}{ }^{-}\right)$using visible-light and persulfate salts $\left(\mathrm{S}_{2} \mathrm{O}_{8}{ }^{2-}\right)$, providing scalable, metal-free, hydrogen-atom transfer (HAT) induced couplings. ${ }^{29,42}$

In spite of such advances, only a limited number of Miniscitype, $\mathrm{C}-\mathrm{H}$-functionalisation methods have been applied to 1,10-phenanthroline substrates. ${ }^{43}$ One of the most recently

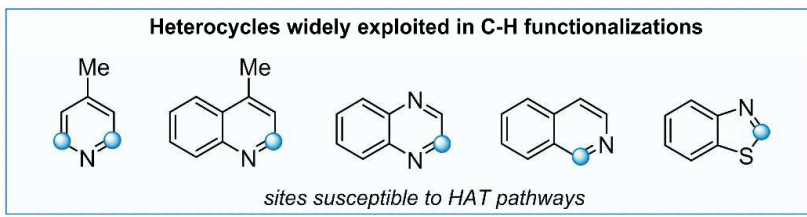

Previous Work:
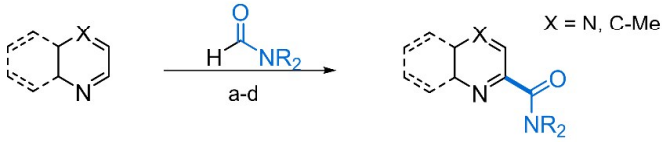

\begin{tabular}{|c|c|c|c|}
\hline a) Minisci[26] & b) Minisci ${ }^{[27]}$ & c) Caronna ${ }^{[28]}$ & d) $\mathrm{Ji}^{[29]}$ \\
\hline $\mathrm{FeSO}_{4} .7 \mathrm{H}_{2} \mathrm{O}$ & $t$-BuOOH & $\mathrm{TiO}_{2}, \mathrm{H}_{2} \mathrm{O}_{2}$ & $\left(\mathrm{NH}_{4}\right)_{2} \mathrm{~S}_{2} \mathrm{O}_{8}$ \\
\hline $\mathrm{H}_{2} \mathrm{O}_{2} / \mathrm{H}_{2} \mathrm{SO}_{4}$ & $\mathrm{Ce}\left(\mathrm{NH}_{4}\right)_{2}\left(\mathrm{NO}_{3}\right)_{6}$ & hv & $\mathrm{PhCHO}$ \\
\hline
\end{tabular}

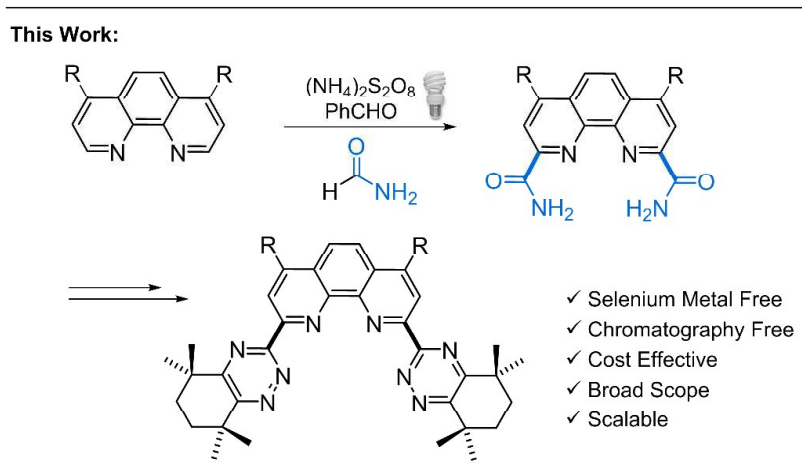

Fig. 1. Photoredox mediated C.-H functionalisations 
reported Minisci-type protocols to include a phenanthroline derivative was reported by Molander et al., and employed Fukuzumi's organophotocatalyst and a range of alkyltrifluoroborates in the presence of stoichiometric $\mathrm{K}_{2} \mathrm{~S}_{2} \mathrm{O}_{8}{ }^{42} \mathrm{xWe}$ recognised the potential for such a protocol and set out to broaden the range of heteroaromatic moieties amenable to visible-light promoted photo-functionalisation. Herein, we report the highly efficient functionalisation of 1,10phenanthroline substrates using a transient $\alpha$-amido radical under mild, metal-free conditions (Fig. 1). Furthermore, we report the application of this protocol towards a significantly improved synthesis of bis-triazinyl-1,10-phenanthroline (BTPhen) ligands.

We initially commenced our studies with more traditional Minisci couplings employing cyclic ethers and peroxides and were able to bis- $\alpha$-alkylate 3,4,7,8-tetramethyl-1,10phenanthroline with 1,3,5-trioxane in $49 \%$ yield. ${ }^{44}$ Although these methodologies provided the desired target molecules, their inefficiencies were soon realised. The chemical lability of 1,3,5-trioxane presented a number of challenges including polymerisation and premature hydrolysis; whilst the need to heat stoichiometric quantities of peroxide to high temperatures proved undesirable. In light of these findings, alternative functionalisation protocols were explored. In particular, we found the use of persulfate salt based initiators to be highly attractive due to their low-cost and variable modes of initiation. We were particularly interested in the installation of nitrile moieties, a common precursor to many heterocyclic cores ${ }^{45-47}$ and a prevalent motif throughout the pharmaceutical industry. ${ }^{48,49}$ Thus, we deduced that amide coupling partners would provide the most efficient access to nitrile bearing frameworks.

The first selective carbomoylation of heteroaromatic bases was reported in 1970 by Minisci and employed metallic salts and peroxides. ${ }^{26}$ Since then, new and improved methodologies have been reported including a visible-light mediated methodology, employing a benzaldehyde photosensitiser, which was found to promote the decomposition of persulfate and thus the generation of the nucleophilic radical species. ${ }^{29}$ We applied a modified procedure to our model 4,7-bis-chloro substrate (1a) and the desired bis-amido heteroarene (2a) was obtained in $82 \%$ yield following irradiation of $\left(\mathrm{NH}_{4}\right)_{2} \mathrm{~S}_{2} \mathrm{O}_{8}$, benzaldehyde and formamide with a $23 \mathrm{~W}$ compact fluorescent lamp (CFL). Furthermore, analytically pure 2a was isolated following a simple filtration and trituration with water and diethyl ether. This protocol was then applied to a diverse range of substrates, which were commercially available or accessible via simple one-step modifications (Table 1). Firstly, a number of versatile halogenated materials including the unsymmetrical 7-chloro (1b) and symmetrical 4,7-bromo (1c) substrates were studied, providing yields of $88 \%$ and $78 \%$, respectively. In an attempt to isolate 2,9-bis-amido-1,10phenanthroline selectively, our procedure was applied to the parent 1,10-phenanthroline core. Even after the addition of 2 equivalents of $\mathrm{H}_{2} \mathrm{SO}_{4}$, none of the desired 2,9-amido product was obtained. We then set out to achieve the first reported tetra-formamidation. Gratifyingly, the desired tetra-amido product (2d) was obtained in $68 \%$ yield. To examine the effects of 3,8-functionalisation on this transformation, both the 4,7-bis-methyl (2e, $75 \%$ ) and 3,4,7,8-tetra-methyl (2f, 62 $\%)$ systems were compared. This $13 \%$ variance in yield may be a result of both increased steric congestion and electron density in the latter. Following this, the substrate series was expanded to incorporate aromatic functionalised systems. The isomeric, aromatic bearing substrates $\mathbf{1 g}$ and $\mathbf{1 h}$ were successfully $\alpha / \mathrm{V}-\mathrm{C}-\mathrm{H}$-functionalised in $75 \%$ and $84 \%$ yields, respectively. The increased yield of $\mathbf{2 h}$ versus $\mathbf{2 g}$ may be attributed to the increased solubility and thus homogeneity of the reaction mixture. Novel bis-(4'-t-Bu-phenyl) $\mathbf{1 i}$ was synthesised in $84 \%$ yield from commercially available 1a, via Suzuki-Miyaura cross-coupling. Subsequent formamidation provided the desired target $\mathbf{2 i}$ in $65 \%$. The 4,7-bis-methoxy substrate $(\mathbf{1 j})$ was also successfully $\alpha-\mathrm{C}-\mathrm{H}$ functionalised albeit in a modest $53 \%$ yield. Notably, no competing abstraction of the additional $\alpha$-oxy $\mathrm{C}-\mathrm{H}$ moieties was observed.

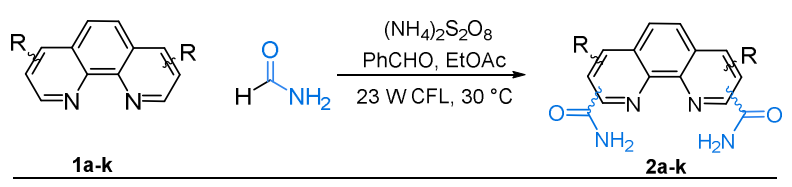

Product, Yield - = new bond formation
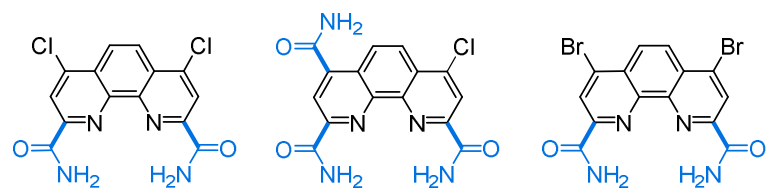

$2 a, 82 \%$ yield

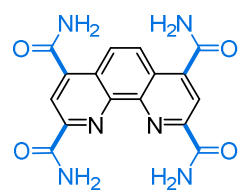

2b, $88 \%$ yield $^{[a][b]}$

2c, $78 \%$ yield
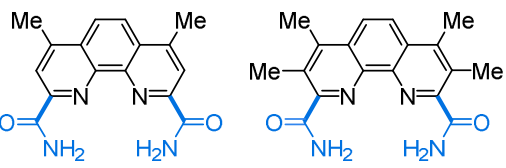

2d, $68 \%$ yield $^{[\mathrm{a}][\mathrm{c}]}$
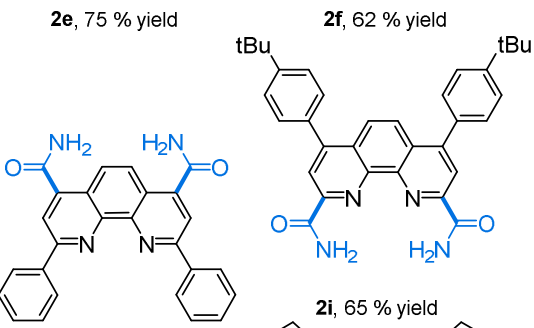

$2 g, 75 \%$ yield

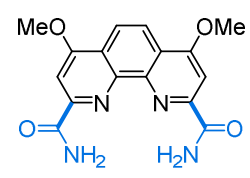

2h, $81 \%$ yield

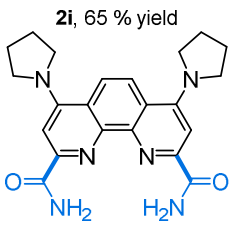

2j, $53 \%$ yield

Table 1: Additional 1,10-phenanthroline substrates employed in the photoredoxmediated $\alpha / \mathrm{Y}-\mathrm{C}-\mathrm{H}$ functionalisations. Reagents and conditions: phenanthroline (1 equiv.), $\left(\mathrm{NH}_{4}\right)_{2} \mathrm{~S}_{2} \mathrm{O}_{8}$ (6 equiv.), benzaldehyde (2.0 equiv.), EtOAc: formamide (1:1), $30{ }^{\circ} \mathrm{C}$. [a] Reagents scaled to account for additional $\mathrm{C}-\mathrm{H}$ sites. [b] Spiked with additional benzaldehyde. [c] $\mathrm{H}_{2} \mathrm{SO}_{4}$ (2 eqvs.) added to promote selective $\alpha$ functionalisation. 
Finally, to explore the substrate tolerance of this methodology further, the pyrrolidine functionalised substrate $\mathbf{1 k}$ was synthesised from 1a. In this instance, the presence of multiple, $\alpha-\mathrm{C}-\mathrm{H}$ moieties gave rise to a variety of additional, unwanted side-reactions and none of the desired $\mathbf{2 k}$ was recovered.

Analysis of the resulting experimental yields reiterates the enhanced susceptibility of electron deficient ring systems towards nucleophillic radical addition. The 4,7 and 7-chloro substrates provided the most efficient conversion whilst the 4,7-methoxy bearing system provided the lowest yield of product. This procedure was found to be amenable to scale-up and targets $\mathbf{2 e}, \mathbf{2 f}, \mathbf{2} \mathbf{g}$ and $\mathbf{2 i}$ were readily prepared in multigram quantities. The efficient $\gamma$-functionalisation exemplified by substrates $\mathbf{2 b}, \mathbf{2} \mathbf{d}$ and $\mathbf{2 h}$ provides a facile route to the immobilisation of 1,10-phenanthroline cores onto a variety of membranes, 2D materials and solid-supports.

The potential for this visible-light promoted functionalisation to provide access to previously inaccessible, $\mathrm{CyMe}_{4}-\mathrm{BTPhen}$ analogues was then examined (Scheme 1). Synthetic precursors $\mathbf{2 e}$ and $\mathbf{2} \mathbf{i}$ were dehydrated using in-situ generated Vilsmeier-Haack reagent to provide bis-nitriles (3a and $\mathbf{3 b}$ ) in $63 \%$ and $85 \%$ yields, respectively. Further reaction of substrates $3 \mathbf{a}$ and $\mathbf{3 b}$ with $\mathrm{N}_{2} \mathrm{H}_{4} \cdot \mathrm{H}_{2} \mathrm{O}$ at ambient temperature, yielded bis-aminohydrazides $4 \mathbf{a}$ (72 \%) and $\mathbf{4 b}$ (95\%). Final coupling with diketone $\mathbf{5 a}$ furnished the desired $\mathrm{CyMe}_{4}-\mathrm{BTPhen}$ analogues $\mathbf{6 a}$ and $\mathbf{6 b}$ in overall yields of $30 \%$ and $36 \%$, respectively.

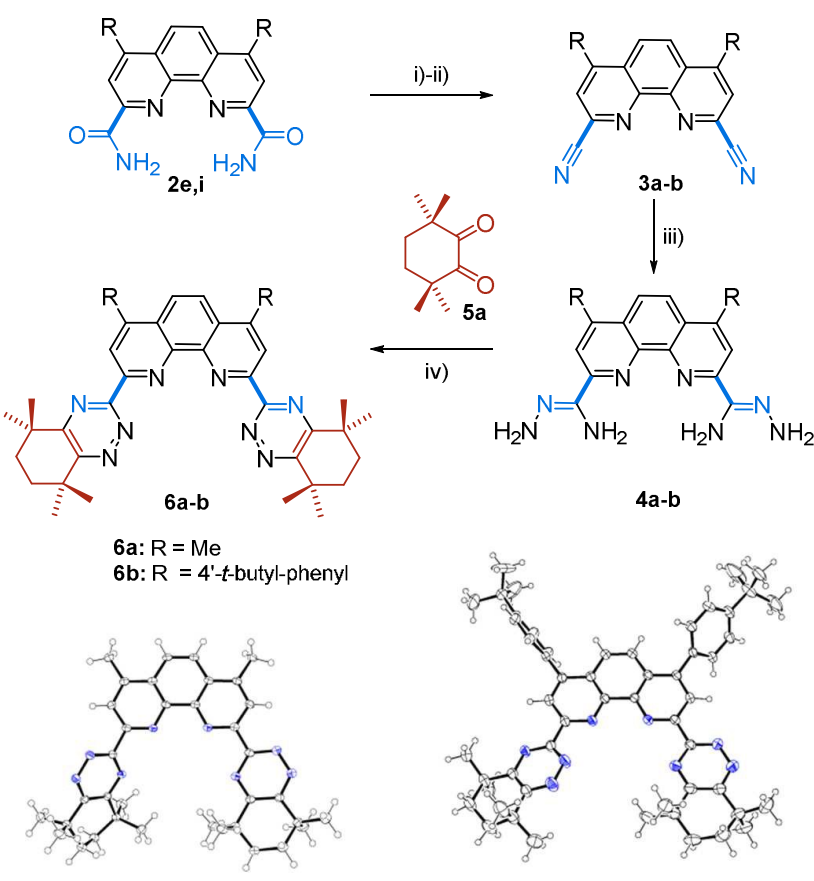

Scheme 1. Synthetic route to $\mathrm{CyMe}_{4}-\mathrm{BTPhen}$ derivatives $\mathbf{6 a}$ and $\mathbf{6 b}$. Reagents and conditions: (i) $(\mathrm{COCl})_{2}, \mathrm{DMF}, 0{ }^{\circ} \mathrm{C}, 5-6 \mathrm{~h}$; (ii) pyridine, $25^{\circ} \mathrm{C}, 1 \mathrm{~h}, 77 \%$ for $3 \mathrm{a}, 85 \%$ for 3b; (iii) $\mathrm{N}_{2} \mathrm{H}_{4} \cdot \mathrm{H}_{2} \mathrm{O}, \mathrm{EtOH}, 25^{\circ} \mathrm{C}, 72 \mathrm{~h}, 72 \%$ for $4 a, 95 \%$ for 4 b; (iv) 5 a (2.2 eqvs), $\mathrm{EtOH}, 78{ }^{\circ} \mathrm{C}, 3 \mathrm{~h}, 71 \%$ for $6 \mathrm{a}$ and $68 \%$ for $6 \mathrm{~b}$. The X-ray crystallographic structures of ligands (6a) and (6b) are shown. Thermal ellipsoids are shown at 50 $\%$ probability. Additional solvent molecules are omitted for clarity.
This new, scalable, visible-light promoted protocol provides significantly enhanced overall yields of $\mathrm{CyMe}_{4}-\mathrm{BTPhen}$ derived compounds compared to previously reported syntheses, including the $\mathrm{SeO}_{2}$ mediated route we previously reported. ${ }^{10,50-52}$ Moreover, this protocol permits access to alkyl-substituted systems without any undesired allylic oxidations.

The 1:1 complex of ligand 6a with $\mathrm{Eu}\left(\mathrm{NO}_{3}\right)_{3}$ was prepared and characterised by single-crystal X-ray diffraction (ESI). The resulting charge neutral, 10-coordinate $\left[\mathrm{Eu}(6 \mathrm{6a})\left(\mathrm{NO}_{3}\right)_{3}\right]$ complex is shown in Fig. S1. Comparison of this complex with that of the free ligand (Scheme 1) highlights the change in molecular conformation when binding to a metallic centre.

The ability of the bis-triazinyl-1,10-phenanthroline (BTPhen) ligands $\mathbf{6 a}$ and $\mathbf{6 b}$ to achieve actinide(III) / lanthanide(III) partitioning was then assessed using ${ }^{241} \mathrm{Am}$ (III) and ${ }^{152} \mathrm{Eu}(\mathrm{III})$ spiked extraction experiments. This separation is a key step in future, nuclear fuel cycles, as it allows for the recycling and reuse of the long-lived minor actinide (Am) in Generation IV reactors, reducing the radioactive burden on geological disposal facilities (GDF). ${ }^{10,53}$ As can be seen from Fig. 2 both ligands $\mathbf{6 a}$ and $\mathbf{6 b}$ gave rise to process-applicable distribution ratios $\left(D_{A m} \geq 50, D_{E u} \leq 5\right)$ at only $2 \mathrm{mmol} / L$ [ligand]. This resulted in excellent actinide selectivity, with separation factors $\left(S F_{\mathrm{Am}(\mathrm{III}) / \mathrm{Eu}(\mathrm{III})}\right)$ ranging between 100 and 225. Furthermore, these ligands exhibited exceptional solubility in 1-octanol (>24 mmol/L), providing a significant step forward from $\mathrm{CyMe}_{4}-\mathrm{BTPhen}^{10}$ and the analogous bi-pyridyl, $\mathrm{CyMe}_{4}{ }^{-}$ BTBP $^{54}$ families, allowing highly concentrated actinide waste streams to be efficiently treated. The observed extraction behaviour of ligands $\mathbf{6 a}$ and $\mathbf{6 b}$ is in accord with our previously published hypothesis on the behaviour of BTPhen systems. ${ }^{52}$

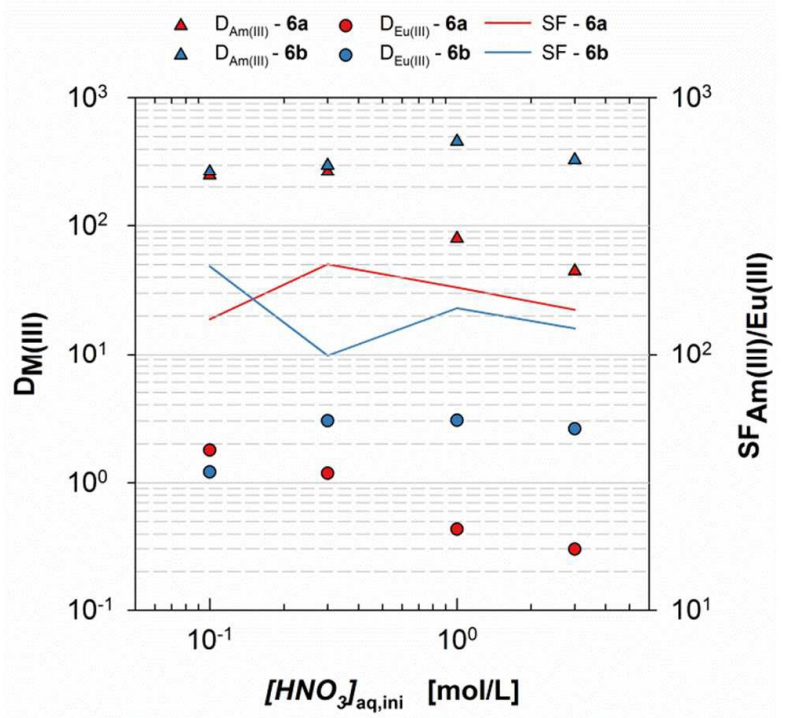

Fig. 2. Extraction of ${ }^{241} \mathrm{Am}(\mathrm{III})$ and ${ }^{152} \mathrm{Eu}(\mathrm{III})$, by 6 a and $6 \mathrm{~b}(2 \mathrm{mmol} / \mathrm{L})$ in 1 -octanol as a function of $\mathrm{HNO}_{3}$ concentration. Shaken at $2500 \mathrm{~min}^{-1}$ for 120 hours at $20{ }^{\circ} \mathrm{C}$

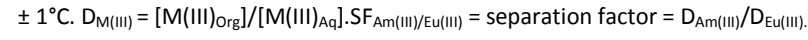


In summary, we have expanded the range of heteroaromatic substrates amenable to visible-light promoted $\alpha / \mathrm{Y}-\mathrm{C}-\mathrm{H}$ functionalisation to include the use of 1,10 phenanthroline systems. We have demonstrated the efficacy of this methodology on a broad range of synthetically divergent substrates and have implemented the first reported tri- and tetra-carbamoylations, providing access to complex molecular frameworks. Further application of this protocol has provided a streamlined, scalable approach to the synthesis of BTPhen ligands that exhibit promising extraction properties and, importantly, enhanced solubility. We anticipate that this methodology will find broad application in the synthesis of phenanthroline derived chelators, solid supports, semiconductors and supramolecular assemblies.

We thank the EPSRC for funding a Nuclear Fission Research, Science and Technology DTC (Nuclear FiRST) studentship EP/G037140/1 (A.C.E).

\section{Notes and references}

1 G. Accorsi, A. Listorti, K. Yoosaf, N. Armaroli, Chem. Soc. Rev. 2009, 38, 1690-700.

2 S. T. Mullins, P. G. Sammes, R. W. West, G. Yahioglu, J. Chem. Soc. Perkin Trans. 1 Org. Bio-Organic Chem. 1996, 24, 75-81.

3 P. G. Sammes, G. Yahioglu, Chem. Soc. Rev. 1994, 23, 327334.

4 W. W. Brandt, F. P. Dwyer, E. D. Gyarfas, Chem. Rev. 1954, 54, 959-1017.

5 C. Dietrich-Buchecker, B. Colasson, D. Jouvenot, J. P. Sauvage, Chem. - A Eur. J. 2005, 11, 4374-4386.

6 C. R. Luman, F. N. Castellano, Compr. Coord. Chem. // 2004, 1, 25-39.

7 J. N. Boodram, I. J. Mcgregor, P. M. Bruno, P. B. Cressey, M. T. Hemann, K. Suntharalingam, Angew. Chem. - Int. Ed. 2016, 55, 2845-2850; Angew. Chem. 2016, 128, 2895-2900.

8 C. Kahlfuss, J. A. Wytko, J. Weiss, Chempluschem 2017, In Press.

9 Y. Sato, R. Yamasaki, S. Saito, Angew. Chem. - Int. Ed. 2009, 48, 504-507; Angew. Chem. 2009, 121, 512-515.

10 F. W. Lewis, L. M. Harwood, M. J. Hudson, M. G. B. Drew, J. F. Desreux, G. Vidick, N. Bouslimani, G. Modolo, A. Wilden, M.

Sypula, et al., J. Am. Chem. Soc. 2011, 133, 13093-13102.

11 H. Niyazi, J. P. Hall, K. O'Sullivan, G. Winter, T. Sorensen, J. M. Kelly, C. J. Cardin, Nat. Chem. 2012, 4, 621-628.

12 K. Hayashi, H. Akutsu, H. Ozaki, H. Sawai, Chem. Commun. 2004, 12, 1386-1387.

13 W. Buratti, G. P. Gardini, F. Minisci, F. Bertini, R. Galli, M. Perchinunno, Tetrahedron 1971, 27, 3655-3668.

14 R. Bernardi, T. Caronna, R. Galli, F. Minisci, M. Perchinunno, Tetrahedron Lett. 1973, 14, 645-648.

15 F. Minisci, E. Vismara, F. Fontana, Heterocycles 1989, 28, 489-519.

16 F. Minisci, F. Fontana, E. Vismara, J. Heterocycl. Chem. 1990 27, 79-96.

17 D. C. Harrowven, B. J. Sutton, S. Coulton, Tetrahedron 2002, $58,3387-3400$.

18 D. C. Harrowven, B. J. Sutton, Prog. Heterocycl. Chem. 2005, 16, 27-53.

19 C. A. Lipinski, J. L. LaMattina, L. A. Hohnke, J. Med. Chem. 1985, 28, 1628-1636.

20 S. Sawada, S. Okajima, R. Aiyama, K. Nokata, T. Furuta, T. Yokokura, E. Sugino, K. Yamaguchi, T. Miyasaka, Chem. Pharm. Bull. (Tokyo). 1991, 39, 1446-1454.

21 N. Kaur, X. Lu, M. C. Gershengorn, R. Jain, J. Med. Chem. 2005, 48, 6162-6165.
22 M. A. J. Duncton, Medchemcomm 2011, 2, 1135.

23 R. Jain, B. Vaitilingam, A. Nayyar, P. B. Palde, Bioorganic Med. Chem. Lett. 2003, 13, 1051-1054.

24 C. K. Prier, D. W. C. MacMillan, Chem. Sci. 2014, 5, 41734178.

25 Y.-Y. Gui, L.-L. Liao, L. Sun, Z. Zhang, J.-H. Ye, G. Shen, Z.-P. Lu, W.-J. Zhou, D.-G. Yu, Chem. Commun. 2017, 111, 1315-1345. 26 G. Gardini, F. Minisci, G. Palla, Tetrahedron Lett. 1971, 12, 59-62.

27 F. Minisci, F. Recupero, C. Punta, C. Gambarotti, F.

Antonietti, F. Fontana, G. F. Pedulli, Chem. Commun. 2002, 21, 2496-2497.

28 T. Caronna, C. Gambarotti, A. Mele, M. Pierini, C. Punta, F. Recupero, Res. Chem. Intermed. 2007, 33, 311-317.

29 Y. Zhang, K. B. Teuscher, H. Ji, Chem. Sci. 2016, 7, 2111-2118.

30 F. Recupero, C. Punta, Chem. Rev. 2007, 107, 3800-3842.

31 J. Jin, D. W. C. MacMillan, Angew. Chem.- Int. Ed. 2015, 54, 1565-1569; Angew. Chem. 2015, 127, 1585-1589.

32 N. Okugawa, K. Moriyama, H. Togo, European J. Org. Chem. 2015, 2015, 4973-4981.

33 D. Hager, D. W. C. MacMillan, J. Am. Chem. Soc. 2004, 136, 16986-16989.

34 A. U. Meyer, A. Wimmer, B. König, Angew. Chem. Int. Ed. 2016, 56, 1-5; Angew. Chem. 2017, 129, 420-423.

35 I. B. Seiple, S. Su, R. A. Rodriguez, R. Gianatassio, Y. Fujiwara, A. L. Sobel, P. S. Baran, J. Am. Chem. Soc. 2010, 132, 1319413196.

36 Y. Fujiwara, V. Domingo, I. B. Seiple, R. Gianatassio, M. Del Bel, P. S. Baran, J. Am. Chem. Soc. 2011, 133, 3292-3295.

37 G.-X. Li, C. A. Morales-Rivera, Y. Wang, F. Gao, G. He, P. Liu, G. Chen, Chem. Sci. 2016, 7, 6407-6412.

38 D. A. DiRocco, K. Dykstra, S. Krska, P. Vachal, D. V. Conway, M. Tudge, Angew. Chem. - Int. Ed. 2014, 53, 4802-4806; Angew. Chem. 2014, 126, 4902-4906.

39 J. Jin, D. W. C. MacMillan, Nature, 2015, 525, 2-5.

40 M. H. Shaw, V. W. Shurtleff, J. A. Terrett, J. D. Cuthbertson, D. W. C. MacMillan, Science, 2016, 6291, 1304-1308.

41 Z. Zuo, H. Cong, W. Li, J. Choi, G. C. Fu, D. W. C. MacMillan, J. Am. Chem. Soc. 2016, 138, 1832-1835.

42 Matsui, J. K.; Primer, D. N.; Molander, G. A. Chem. Sci. 2017, 8, 3512-3522.

43 A. P. Antonchick, L. Burgmann, Angew. Chem. - Int. Ed. 2013, 52, 3267-3271; Angew. Chem. 2013, 125, 3349-3353.

44 C. Giordano, F. Minisci, E. Vismara, S. Levi, J. Org. Chem. 1986, 51, 536-537.

45 K. S. Yeung, M. E. Farkas, J. F. Kadow, N. A. Meanwell, Tetrahedron Lett. 2005, 46, 3429-3432.

46 D. Cantillo, B. Gutmann, C. O. Kappe, J. Am. Chem. Soc. 2011, 133, 4465-4475.

47 H. Xu, S. Ma, Y. Xu, L. Bian, T. Ding, X. Fang, W. Zhang, Y. Ren, J. Org. Chem. 2015, 80, 1789-1794.

48 F. F. Fleming, L. Yao, P. C. Ravikumar, L. Funk, B. C. Shook, J. Med. Chem. 2010, 53, 7902-7917.

49 J. Kim, H. J. Kim, S. Chang, Angew. Chem. - Int. Ed. 2012, 51, 11948-11959; Angew. Chem. 2012, 124, 12114-12125.

50 A. Afsar, D. M. Laventine, L. M. Harwood, M. J. Hudson, A. Geist, Chem. Commun. 2013, 49, 8534-6.

51 A. Afsar, L. M. Harwood, M. J. Hudson, J. Westwood, A. Geist, Chem. Commun. 2015, 51, 5860-5863.

52 A. C. Edwards, C. Wagner, A. Geist, N. A. Burton, C. A. Sharrad, R. W. Adams, R. G. Pritchard, P. J. Panak, R. C. Whitehead, L. M. Harwood, Dalt. Trans. 2016, 45, 18102-18112. 53 F. W. Lewis, L. M. Harwood, M. J. Hudson, A. Geist, V. N. Kozhevnikov, P. Distler, J. John, Chem. Sci. 2015, 6, 4812-4821. 54 C. Ekberg, E. Aneheim, A. Fermvik, M. Foreman, E. LöfströmEngdahl, T. Retegan, I. Spendlikova, J. Chem. Eng. Data 2010, 55, 5133-5137. 


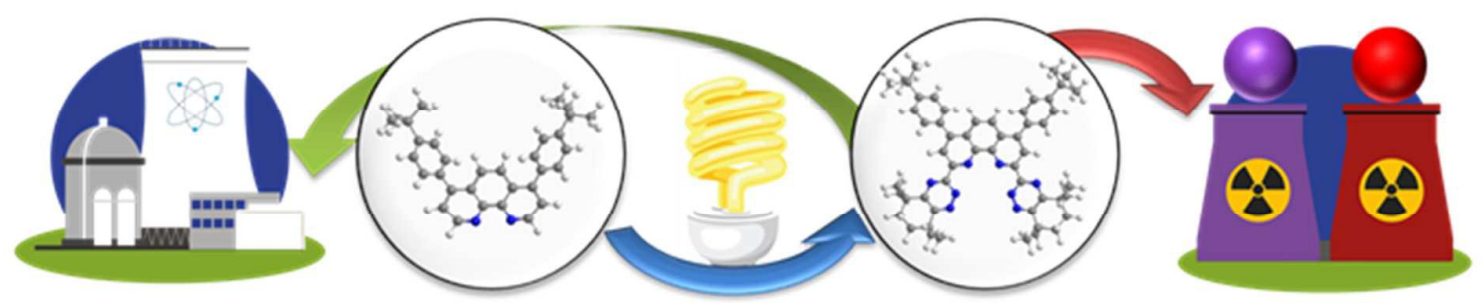

An efficient, visible-light mediated, mild and metal-free strategy for the direct $\alpha$ - and $y$-functionalisation of 1,10phenanthrolines is reported. 